\title{
UNAPREĐENJE LOGISTIČKIH PROCESA NABAVKE, SKLADIŠTENJA I TRANSPORTA U PREDUZEĆU „HUTCHINSON“ RUMA
}

\section{IMPROVEMENT OF LOGISTICS' PROCESSES OF PROCUREMENT, WAREHOUSING AND TRANSPORT IN THE COMPANY „HUTCHINSON“ RUMA}

\author{
Ljubica Jelača, Fakultet tehničkih nauka, Novi Sad
}

\section{Oblast - INDUSTRIJSKO INŽENJERSTVO I MENADŽMENT}

Kratak sadržaj - U ovom radu je prikazan značaj logističkih procesa nabavke, skladištenja $i$ transporta $i$ njihova primena u preduzeću „Hutchisnon“. Uočeni su nedostaci i predložena potencijalna unapređenja. Potencijalna unapređenja se ogledaju u uređenju skladišta kroz obeležavanje skladišnih lokacija i transportnih puteva, zapošljavanju novog lica u skladištu, pravilnim odabirom podobnih dobavljača i obeležavanje kutija.

Ključne reči: Logistika, nabavka, skladištenje i transpot. Abstract - In this research paper the importance of logistics processes is shown, such as procurement, warehousing and transort and their application in enterprise ,Hutchinson“. Some of the setbacks have been noticed and the appropriate measures for improvement have been proposed. Potential improvements have been seen through: warehouse management through marking of storage locations and transportation roads, new employee in warehouse, correct choose of suppliers and marking of boxses.

Keywords: Logistics, processes of procurement, warehousing and transport.

\section{UVOD}

Predmet rada je objasniti važnost logistike i logističkih procesa u preduzeću, i ukazati na važnost implementacije logističkih aktivnosti kako bi preduzeće moglo rasti i razvijati se. Dobro organizovanim i efektivnim sprovođenjem logističkih aktivnosti, preduzeće može ostvariti svoje ciljeve, misiju i viziju, konkurentsku prednost, a ujedno i zadovoljiti zahteve i potrebe kupaca. Preduzeće u kojem će se analizirati mogućnosti unapređenja menadžmenta logistikom zove se „Hutchinson”, i nalazi se u Rumi. Osnovna delatnost ovog preduzeća je proizvodnja plastičnih creva za proticanje goriva i proizvodnja gumenih creva kroz koje prolazi voda. Logistički procesi na koje je stavljen akcenat $\mathrm{u}$ ovom radu su nabavka, skladištenje i transport.

"Preduzeće je privredni subjekt u okviru koga se, u robno - novčanoj privredi obavlja određena privredna delatnost”. To bi bilo po definiciji šta je preduzeće, Korsel Seneju definiše kao „Svaku ljudsku aktivnost koja

\section{NAPOMENA:}

Ovaj rad proistekao je iz master rada čiji mentor je bio dr Stevan Milisavljević, vanr. prof. koristi razne sile da bi ostvarila određeni cilj“. Po tržišnom konceptu „Svaki samostalni finansiski subjekt koji proizvodi za tržište robu ili usluge“ predstavlja preduzeće [1].

\section{RAZVOJ I OPŠTA PRIČA O LOGISTICI}

Logistika je veoma stara oblast poslovanja koja se usavršavala paralelno sa razvojem civilizacije. Kao stara oblast poslovanja, logističke aktivnosti sreću se kod velikih seoba naroda $\mathrm{i}$ brojnih ratova kojima je bila potrebna logistička podrška. U savremenim uslovima poslovanja logistika se posmatra kao mlada naučna disciplina i istovremeno kao savremena i nova oblast poslovanja. Po drugima reč "logistikos" predstavlja čoveka koji ispravno procenjuje i brzo odlučuje, predstavlja veštinu, iskustvo i znanje potrebno za rešavanje strateških i taktičkih zadataka u svim područjima ljudskih aktivnosti. Po nekima je reč logistika Iranskog porekla što predstavlja "loger" - nastanak [2].

\section{NABAVKA}

„Nabavka je funkcija preduzeća koja se brine da organizacija bude obezbeđena svim potrebnim sirovinama, poluproizvodima, uslugama i ostalim sredstvima neophodnim za neprekinuto odvijanje procesa proizvodnje, odnosno pružanja usluge, ako je to osnovna delatnost organizacije“" [3].

Nabavka je osnovna i suštinska funkcija u svakoj organizaciji. Svakoj organizaciji je potrebno snabdevanje materijalima, a nabavka je zadužena za organizaciju takvih aktivnosti. Ako je nabavka loše sprovedena, dešava se da materijali ne stignu od dobavljača, ili se isporuči pogrešan materijal, u pogrešnim količinama, u pogrešno vreme, lošeg kvaliteta, po suviše visokoj ceni, itd. Služba nabavke mora biti dobro povezana sa ostalim odeljenjima u preduzeću. Pojedina odeljenja u zavisnosti od svoje poslovne funkcije mogu pred nabavku postaviti različite zadatke za snabdevanje. Zato funkcija snabdevanja predstavlja vezu između organizacionih celina preduzeća i raznih snabdevača koji žele nešto da prodaju preduzeću.

\section{SKLADIŠTENJE}

Skladište je prostor gde kompanija čuva sirovine, polu proizvode ili gotove proizvode prikazano na slici 1., gde su sirovine, polu proizvodi, gotovi komadi u rasutom stanju ili u ambalaži sa namerom da posle određenog vremena roba bude uključena $u$ daljnji transport, 
proizvodnju, distribuciju ili potrošnju [4]. Odlaganje i čuvanje proizvoda u skladištu zaustavlja ili prekida tok robe, dodajući troškove proizvodima. Neke kompanije nastoje da ih zaobiđu i imaju negativan stav prema skladištu. Takav stav menja zahvaljujući shvatanju da skladištenje više može da poveća vrednost proizvodu nego troškove. Druge firme, posebno distributeri ili velikoprodavci su otišli u drugu krajnost i skladište sve proizvode.

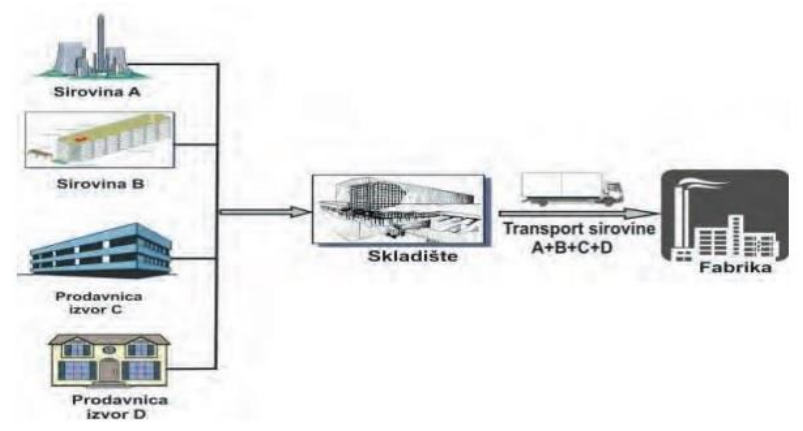

Slika 1. Sistem isporuke sirovina i komponenti

Neke od najvažnijih uloga skladišta u logističkom sistemu su: konsolidacija transporta, miksovanje proizvoda, pružanje usluga i zaštita od nepredviđenih okolnosti. Način čuvanja robe u skladištu mora da bude takav da obezbeđuje da roba prilikom mirovanja zadržava sva upotrebna svojstva u dozvoljenim granicama. Zadatak skladišta je da prihvati robu na kraju određenog transportnog ili proizvodnog procesa na mestima koja su pogodna za smeštaj robe, kako bi se ta roba kasnije mogla dalje koristiti.

\section{TRANSPORT}

Transport predstavlja jednu od najznačajnijih logističkih funkcija. Zauzima prvo i poslednje mesto u proizvodnom procesu, odnosno podrazumeva transport sirovina za proizvodnju i transport gotovog proizvoda do potrošača. Zaustavljanje transporta, značilo bi i zaustavljanje same proizvodnje. Pod transportom u užem smislu se podrazumeva prevoz stvari sa jednog mesta na drugo, pod transportom u širem smislu se podrazumevaju sve aktivnosti neophodne za obavljanje prevoza i drugih prevoznih radnji, čuvanje i obezbeđivanje stvari i dokumetacije tokom transportnog procesa.

\section{STUDIJA SLUČAJA}

Studija slučaja i rešavanje problema primenjena je $u$ preduzeću „Hutchinson“. Kompanija se sastoji iz dve divizije. Divizija „Voda” eng. „Water” i „Gorivo” eng. „Fuel”. Podela je izvršena na osnovu strukture creva $\mathrm{i}$ tuba koje se proizvode, a kroz koje protiče tečnost (eng. Fluid). Svrha kompanije je da uspostavi i unapređuje organizaciju koja je usredsređena na zadovoljenje zahteva kupca za kvalitet i isporuku na vreme. Koriste znanja i veštine zaposlenih i unapređuju ih pomoću obuka i usavršavanja. Sve aktivnosti obavljaju u skladu sa zahtevima odgovarajućih pravnih normi i međunarodnih standarda kvaliteta. Unapređuju bezbednost na radu, zaštitu okoline, proizvode i način na koji nastaju.
Očekivanja kupca se zadovoljavaju, tako da se istovremeno zadovolje očekivanja zaposlenih, dobavljača, vlasnika i društva.

U nastavku su dati opisi pomenutih funkcija u preduzeću, prikazan je način rada pomenutih odeljenja, i potom je za uočene nedostatke predloženo nekoliko mogućih mera unapređenja.

\section{SNIMAK STANJA POSMATRANIH PROCESA}

\subsection{Principi organizacije nabavke, skladištenja i transporta u preduzeću „Hutchinson“ Ruma.}

Zadatak nabavke nije samo obezbeđenje materijala za obezbeđenje procesa proizvodnje, već je njen zadatak razumevanje organizacije i poslovanja isporučilaca i njihove prednosti i slabosti. Ako je nabavka loše sprovedena, dešava se da materijali ne stignu od dobavljača, ili se isporuči pogrešan materijal, u pogrešnim količinama, u pogrešno vreme, lošeg kvaliteta, po suviše visokoj ceni...

Poručene komponente od dobavljača, kao i gotovi komadi koji se šalju kupcu ili u eksterni magacin, treba da se odlože da određeno mesto pre slanja ili pri prijemu, a to mesto je upravo skladište.

Kako bi kompanija napravila plan za nabavku određenih komponenti prvo mora da postoji porudžbina za određenim proizvodima i definisan plan proizvodnje istih. Porudžbine od korisnika se primaju u elektronskom obliku ili u papirnom obliku, preko E-maila ili fax-a.

Specijalista logistike na dnevnom nivou radi analize porudžbina na osnovu porudžbenica i najava. U slučaju velikih odstupanja od najavljivanih količina, obaveštava korisnika i u slučaju da je to neophodno, dodatne isporuke se ugovaraju u cilju sprečavanja specijalnih prevoza i kašnjenja.

$\mathrm{Na}$ osnovu narudžbina gotovih proizvoda, specijalista logitike određuje potrebu za komponentama neophodnih za proizvodnju. Kad naručene komponente stignu u fabriku vrši se njihova kontrola. Kontrola se vrši jer mogu da se jave određene neusklađenosti: manjak u odnosu na poručenu količinu, višak u odnosu na poručenu količinu, neodgovarajići kvalitet i oštećena pošiljka. Proizvodi koji se kupuju kao repromaterijal čuvaju se u originalnoj ambalaži sve do potrebe za istim, nakon toga se stavljaju u plastične kutije.

Komponente i gotovi proizvodi se odlažu u skladište. Lokalna skladišta zauzimaju znatno manju površinu od centralnih skladišta, i imaju ograničene kapacitete. Stoga je od velike važnosti da lokalna skladišta budu dobro organizovana po pitanju iskorišćenja skladišnog prostora, načina rasporeda robe $i$ materijala $u$ skladišnim jedinicama, mogućnostima kretanja transportnih mašina, pravilnog obeležavanja transportnih puteva i pešačkih zona, kako bi se iz raspoloživog skladišnog prostora izvukao maksimum. 


\section{KRITIČKI OSVRT}

Prilikom sprovođenja procesa nabavke, kompanija se neretko suočava sa dobavljačima koji ne ispune sve ono što je ugovorom dogovoreno. Poručeni materijal kasni, ne stiže u dogovorenoj količini, i dogovorenom kvalitetu. Pomenuti problemi znatno otežavaju normalno funkcionisanje odeljenja nabavke, i sprovođenje samog postupka. Jasno je da bi adekvatan odabir dobavljača znatno promenio ovakvo stanje.

Što se tiče procesa skladištenja, problem nastaje prilikom zaprimanja robe u skladište. Naime, nakon što šef skladišta izvrši kvantitativnu i kvalitativnu kontrolu prispelog materijala i proizvoda, dešava se da ne ažurira stanje novoprispele robe u aplikaciji koja ovo odeljenje povezuje sa nabavkom i prodajom. Usled nedostatka kadra u pojedinim skladištima, šef skladišta ima previše zadataka, pa mu ažuriranje aplikacije svakako nije prioriteno, u odnosu na druge probleme koji se mogu javiti u skladištu. Tako dolazi do usporavanja postupka prodaje, ali i nabavke.

Drugi problem koji se javlja prilikom funkcionisanja skladišnih procesa je taj što skladišta nisu adekvatno obeležena u smislu saobraćajnih oznaka. Putevi za kretanje transportnih sredstava kao ni pešačke zone nisu obeleženi, pa dolazi do usporavanja postupaka manevrisanja sa skladišnom robom, što je opet nepotrebni gubitak.

Dijagram UZROCI - POSLEDICA, još je poznat i pod nazivom Fishbone - Riblja kosta ili Ishikawa dijagram. Ovaj dijagram predstavlja inženjersku metodu za identifikovanje, razvrstavanje i prikaz potencijalnih uzroka nastanka određenog problema. $\mathrm{Na}$ slici 2. je prikazan Ishikawa dijagram sa identifikovanim nedostacima, odnosno uzrocima koji dovode do poteškoća prilikom obavljanja procesa nabavke, prodaje i skladištenja.

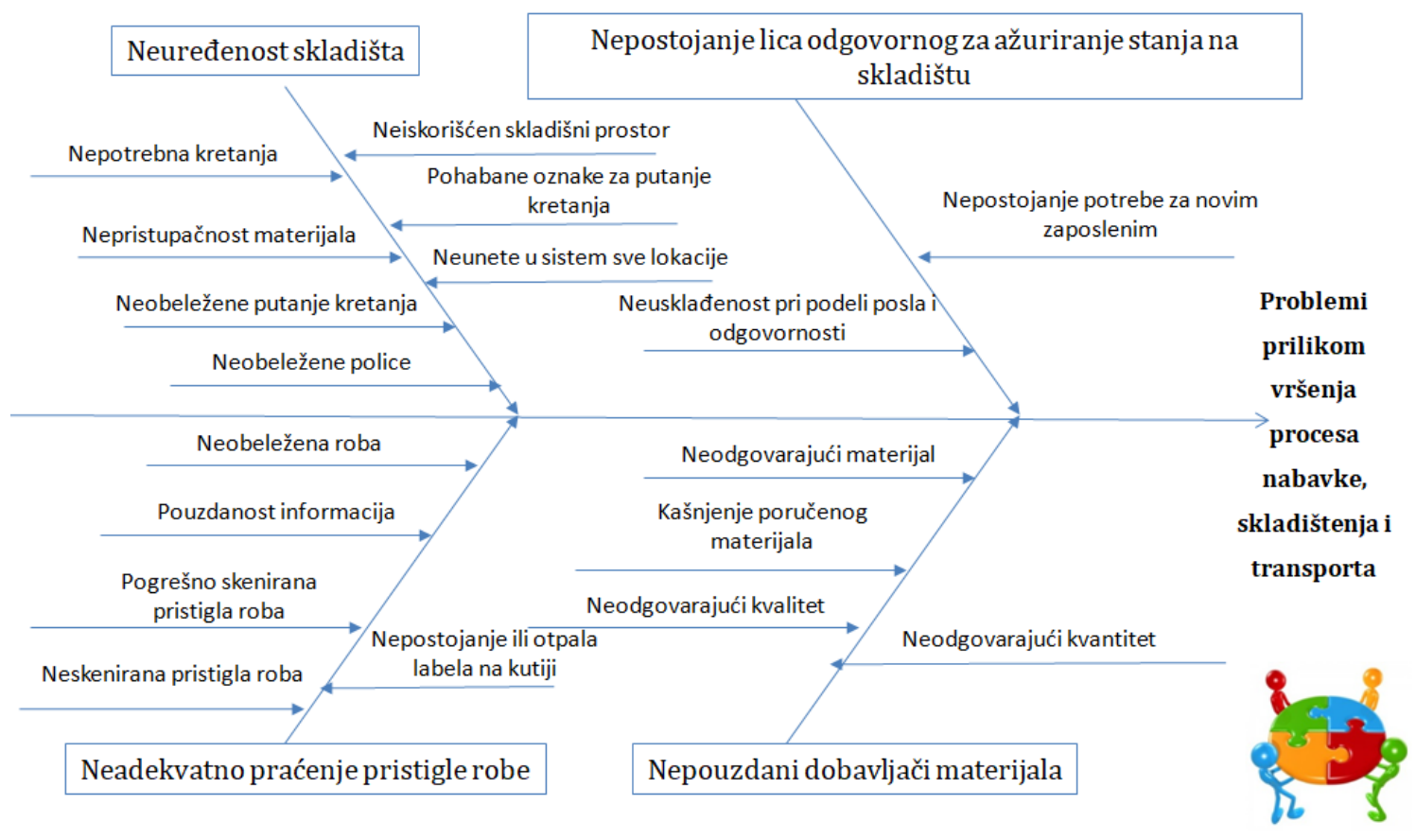

Slika 2. Ishikawa dijagram

\section{PREDLOG ZA MERE UNAPREĐENJA}

\subsection{Obeležavanje skladišnih lokacija i transportnih puteva}

Ukoliko želimo da radnici daju svoj maksimum i rade najbolje, mora im se obezbediti i najbolje radno okruženje. Potrebno je povećati efikasnost skladišta kroz njegovu organizaciju. Organizacijom skladišta će se eliminisati gubici koji su nastali kao posledica "nekontrolisanih" procesa. Prvi korak ka povećanju efikasnosti je uklanjanje svih nepotrebnih stvari iz skladišta.

U skladištima se nalaze prazne kutije, alat koji više nije u funkciji, otpad itd. Kada su sve nepotrebne stvari uklonjene, potrebno je pronaći odgovarajuće mesto za sve ono što je u magacinu.

Jedan od predloga bi bio da se obeleže sve putanje kretanja, pešačke zone, zone za viljuškare, paletare, zatim police, palete... Prostor unutar magacina bi se podelio na deo gde su komponente, i samo na taj prolaz bi smeo da stane kamion koji donosi komponente od dobavljača. Kamioni koji odvoze gotove komade u eksterni magacin bi bile na drugom ulazu i kamioni koji spremaju isporuku bi bili na posebnom ulazu, napravila bi se i označila zona za spremanje isporuke.

Napravila bi se procedura za pravilno obeležavanje kao i dodeljivanje lokacije na skladištu, kako ne bi došli u situaciju da se koriste skladišta koja su ne obeležena, gde nije definisana zona kretanja kao ni lokacije.

Time bi se ostvarila reorganizacija skladišta. Kutije se ne bi,svuda" stavljale, prostor za isporuku bi bio definisan i ne bi došlo do toga da se kutije izgube. Izvršila bi se obuka za sve zaposlene o zonama kretanja. 


\subsection{Nepostojanje odgovornog lica za ažuriranje sistema o pristigloj robi}

Predlog za unapređenje bi bio da se zaposli jedna osoba u skladištu čiji bi osnovni zadatak bio da redovno prati promene koje se dešavaju na skladištu, i da redovno vrši ažuriranje aplikacije nakon što roba je zaprimljena u skladište. Čim nova roba i materijal pristigne u skladište, novozaposleni treba da otvori u aplikaciji šifru te robe $\mathrm{i}$ unese sve potrebne podatke o novom stanju pristigle robe na lageru. Unošenje se vrši putem računara. Zapošljavanjem jedne osobe koja bi redovno ažurirala stanje robe u skladištu bi se poboljšala saradnja prodaje i skladišta, jer bi prodaja bila sigurna da je uvek u toku sa najnovijim dešavanjima u skladištu, koja su relevantna za njeno poslovanje.

\subsection{Nepouzdani dobavljači}

Potrebno je da se zaposleni u sektoru nabavke edukuju putem odlaska na seminare, kako bi bili u mogućnosti da sprovode aktivnosti pravilnog izbora najpodobnijih isporučilaca/dobavljača. Putem seminara, zaposleni bi naučili kako se vrši postupak ocene i izbora najpouzdanijih isporučilaca, koji su to kriterijumi i faktori presudni za izbor. Na osnovu raznih kriterijuma, i izvršenog ocenjivanja, dobiju se isporučioci koji ispunjavaju zahteve, i oni ulaze u registar isporučilaca. Na kraju se napravi izveštaj koji sadrži naziv dobavljača, klasifikaciju dobavljača, sugestije za poboljšanje kvaliteta i zaključak, i taj se izveštaj prosleđuje ostalim odeljenjima u preduzeću.

\subsection{Neadekvatno praćenje pristigle robe}

Uočeno je da roba koja pristigne u skladište od dobavljača, nema adekvatno praćenje kroz skladišni prostor $u$ smislu obeleženosti materijala, lokacijiskih jedinica na koje je roba smeštena. Kako bi stanje materijala i robe na skladištu bilo dostupno i poznato u svakom trenutku, potrebno je kao što je navedeno zaposliti osobu koja će to i pratiti. Materijal se trenutno obeležava od strane šefa skladišta, kreiranjem labele i na kraju određivanjem gde će lokacijski zaprimljena roba biti smeštena, jer šef skladišta ima veliku odgovornost i preobimnost posla, tako da osoba koja bi pratila i kontrolisala unos robe bila bi od velikog značaja.

Dešava se da labele spadnu sa robe, izgube se, što dodatno otežava njihovo praćenje i dalju manipulaciju. Najčešće se problem javlja kod gotovih proizvoda. Kutije su drvene i plastične. Jedan od rešenja jeste da se labele stavljaju u vreću i zatim spajaju heftalicom.

\section{ZAKLJUČAK}

Logistika se može definisati na razne načine, postoje brojne definicije i mišljenja. Međutim u središtu svih definicija stoji činjenica da je logistika celokupan proces $\mathrm{i}$ način upravljanja svim aktivnostima tokova od nastanka proizvoda, pa sve do isporuke proizvoda krajnjim kupcima, dakle sve ono što je potrebno za izvršavanje osnovnih delatnosti jednog preduzeća.

Kako bi ovaj cilj bio ispunjen od ključnog značaja je za jedno trgovnisko preduzeće da uspešno sprovodi i stalno unapređuje logistične procese nabavke, skladištenje i transport.

Kompanija „Hutchinson“ se nalazi u Rumi, autoindustrija, bavi se proizvodnjom plastičnih creva za proticanje goriva i gumena creva kroz koje prolazi voda.

Upoznata sa radom preduzeća, uvidela sam neke propuste i pomoću dijagrama „Išikava“ predstavljeni su svi problemi koji se javljaju u procesu nabavke, skladištenja i transporta. Izvršene su mere unapređenja za pomenute procese i izvršena je finansijka analiza.

\section{LITERATURA}

[1] Nenad D.Penezić, Teorija ekonomije preduzeća, Novi Sad, 2015

[2] Regodić, D., Logistika lanci snabdevanja, ISBN: $978-$ 86-7912-564-4, Univerzitet Singidunum, Beograd, 2014

[3] Beker, I. Stanivuković, Logistika - Integralna sistemska podrška. Fakultet Tehničkih Nauka, Novi Sad, 2012

[4] Nikoličić, S., Stojanović, Đ., Maslarić, M., Osnovi logistike: principi, sistemi i procesi, Fakultet tehničkih nauka, Novi Sad, 2016

\section{Kratka biografija:}

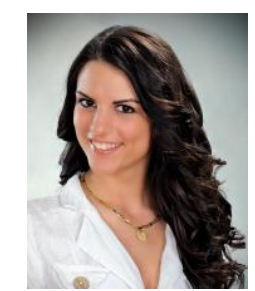

Ljubica Jelača rođena je u Vrbasu 1993. god. Master rad na Fakultetu tehničkih nauka iz oblasti Industrijsko inženjerstvo - Kvalitet i logistika, odbranila je 2019.god.

kontakt: ljubicajelaca@ hotmail.rs. 